\title{
Geotechnical centrifuge modelling of retrogressive sensitive clay landslides
}

\author{
Ray Kennedy, W. Andy Take, and Greg Siemens
}

\begin{abstract}
Sensitive clay landslides represent a significant geohazard due to their well-known potential for extensive retrogressive failures, on the scale of multiple hectares, which could encompass surrounding communities and infrastructure. Interpretation of retrogression mechanisms is often limited as only forensic investigations are possible. This work presents the results of a physical modelling study to examine retrogressive failures, analysis of each failure episode, and interpretation of the results using published relationships. Five novel centrifuge model tests were conducted under a defined range of undrained shear strength and slope angle conditions. The models are constructed of a sensitive cement-soil mixture that allows for a consistent contractile material with bespoke shear strength. Results indicate the observed retrogression distance correlates with Taylor's stability number. The addition of a $5^{\circ}$ slope angle to invoke a static shear stress on the model provoked notably larger retrogression distances. Post-test undrained shear strength measurements quantified softening of the material along the failure surface. Stability analyses on each failure episode captured the observed failure geometry and factor of safety. Results indicate that the geometric parameters of a slope, specifically the slope angle, may be able to explain a component of the scatter for relating Taylor's stability number with retrogression distances.
\end{abstract}

Key words: retrogressive landslides, sensitive clay, soil-cement mixtures, physical modelling, centrifuge modelling.

Résumé : Les glissements de terrain d'argile sensible représentent un géorisque important en raison de leur potentiel bien connu de défaillances régressives étendues, à l'échelle de plusieurs hectares, qui pourraient englober les communautés et les infrastructures environnantes. L’interprétation des mécanismes de régression est souvent limitée, car seules les enquêtes médicolégales sont possibles. Ce travail présente les résultats d'une étude de modélisation physique visant à examiner les défaillances régressives, l'analyse de chaque épisode de défaillance et l'interprétation des résultats à l'aide des relations publiées. Cinq nouveaux essais sur des modèles de centrifugeuses ont été réalisés dans une gamme définie de conditions de résistance au cisaillement sans consolidation et d'angle d'inclinaison. Les modèles sont construits à partir d'un mélange sensible de ciment et de terre qui permet d'obtenir un matériau contractile constant avec une résistance au cisaillement sur mesure. Les résultats indiquent que la distance de régression observée est en corrélation avec l'indice de stabilité de Taylor. L'ajout d'un angle d'inclinaison de $5^{\circ}$ pour invoquer une contrainte de cisaillement statique sur le modèle a provoqué des distances de régression nettement plus importantes. Les mesures de la résistance au cisaillement sans consolidation après l'essai ont quantifié le ramollissement du matériau le long de la surface de défaillance. Des analyses de stabilité sur chaque épisode de défaillance ont permis de saisir la géométrie de défaillance observée et le facteur de sécurité. Les résultats indiquent que les paramètres géométriques d'une pente, en particulier l'angle de la pente, peuvent expliquer une composante de la dispersion pour relier l'indice de stabilité de Taylor aux distances de régression. [Traduit par la Rédaction]

Mots-clés : glissements de terrain régressifs, argile sensible, mélanges sol-ciment, modélisation physique, modélisation par centrifugeuse.

\section{Introduction}

Retrogressive landslides in sensitive clay soils are a significant hazard to both infrastructure and residents of Eastern Canada and parts of Scandinavia, among other regions. Figure 1 illustrates a retrogressive failure where an initial rotational movement is sufficiently mobile to vacate the source region and lead to successive slope movements. The extent of this hazard is represented by the retrogression distance, defined as the distance from the top of the original slope to the crown of the post-failure slope (e.g., the zone of depletion). "Large retrogressive landslides" are defined as slope movements in which the retrogression distance exceeds the original slope height by a factor of two. In Quebec, large retrogressive landslides that are 1 ha or greater occur every 2.3 years (Potvin et al. 2014). Quinn et al. (2011a) reported an extensive historical review and noted that the severity of these events is such that buildings and infrastructure located within the craters of retrogressive landslides were destroyed in every case. In Canada, retrogressive landslides are a significant hazard to the residents and infrastructure located within the limits of the post-glacial Champlain

Received 17 October 2019. Accepted 1 November 2020.

R. Kennedy and W.A. Take.* GeoEngineering Centre at Queen's-RMC, Department of Civil Engineering, Queen's University, Kingston, ON K7L 3N6, Canada. G. Siemens.* GeoEngineering Centre at Queen's-RMC, Department of Civil Engineering, Royal Military College of Canada, Kingston, ON K7K 7B4, Canada.

Corresponding author: Greg Siemens (email: Greg.Siemens@rmc.ca).

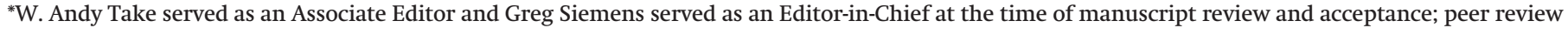
and editorial decisions regarding this manuscript were handled by Elisabeth Bowman.

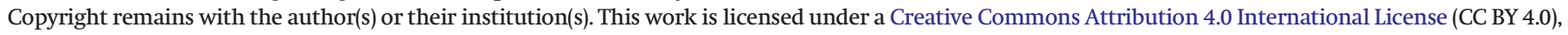
which permits unrestricted use, distribution, and reproduction in any medium, provided the original author(s) and source are credited. 
Fig. 1. Schematic of retrogressive sensitive clay flowslide, where $(a)$ initial rotational failure vacates source region to create another unstable failure. Rapid, successive undrained failures occur in retrogressive fashion with each failure overcoming greater shear resistance until (b) stable condition is achieved (Bjerrum 1967).

\section{a) Sequential Retrogression Failure Process}

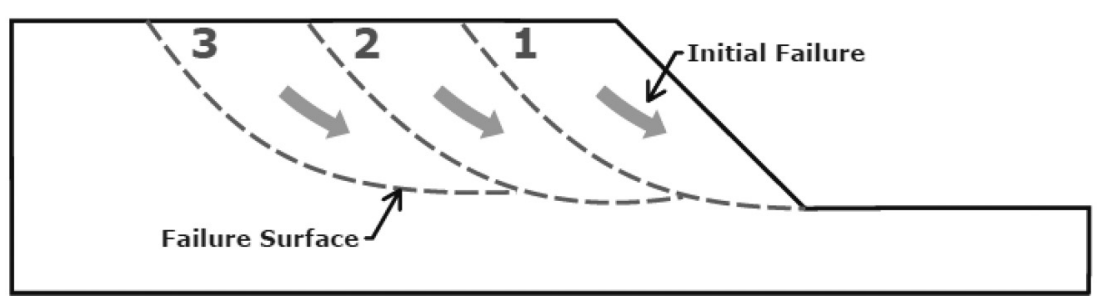

\section{b) Final Deposit Morphology}

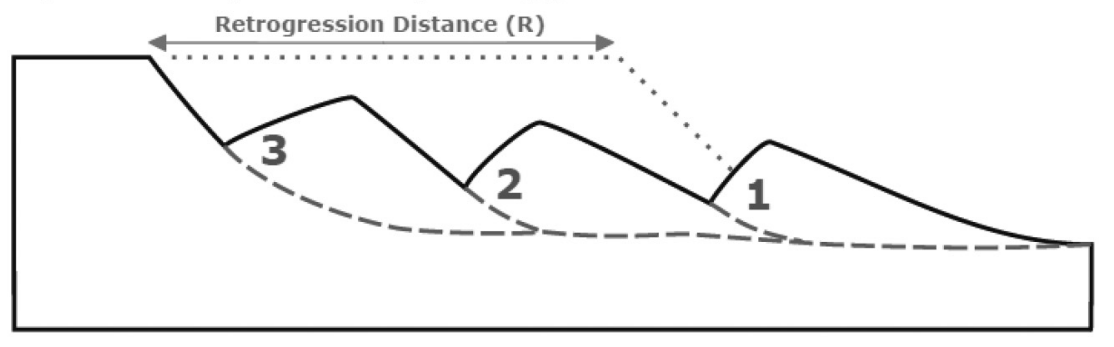

Sea, a region of abundant clay deposits along modern-day Ottawa River, St. Lawrence River, and Saguenay River.

Sensitive clay slope movements in Eastern Canada take on several forms, that may vary in terms of the mechanism of retrogression. Locat et al. (2011) observed that single rotational slides, multiple retrogressive slides, translational progressive slides, and spreads are the main types of sensitive clay movements in Canada and Scandinavia. Deep-seated rotational failures are common in low permeability, saturated soils (Hungr et al. 2014). Movement is primarily rotational in an axis parallel to the slope. Slides in sensitive clays are usually very rapid, augmented by a considerable amount of strength loss. Hungr et al. (2014) defined multiple retrogressive slides and translational progressive slides as "sensitive clay flowslides", characterized by rapid strength loss due to sudden remolding and often the failed material vacating the source zone (e.g., Locat et al. 2017). Figure 1 shows how, in many cases, a rotational slide is merely the initial stage of larger retrogressive movement (e.g., Varnes 1978; Hungr et al. 2014). These events involve multiple rotational slides following an initial slide in a rapid sequence (e.g., Varnes and Cruden 1996; Locat et al. 2017). Multiple rotational slides are possible if the failed material flows out of the crater and leaves an unstable backscarp, which then fails under undrained conditions. Translational progressive slides, illustrated on Fig. 2, are described as "extremely rapid lateral spreading of a series of coherent clay blocks, floating on a layer of remoulded sensitive clay" (Hungr et al. 2014). Figure 2 shows how these failures result from a quasi-horizontal shear zone propagating back from the slope toe (e.g., Locat et al. 2011; Quinn et al. 2011b). The failure surface, referred to as the post-peak shear zone, extends horizontally until horizontal pressures in the slope reach active failure. Figure $2 b$ illustrates how a lateral spread occurs with the overlying soil mass segmenting into horst and graben structures and migrating laterally away from the backscarp on the further remolded material. Due to the variation in the types of slides observed in Canada, retrogression distance calculations must consider both multiple retrogressive slides and translational progressive slides.

Field studies consolidating historical sensitive landslides provide a framework to relate retrogression distance to readily estimated parameters. Figure 3a shows Mitchell and Markell (1974) data relating Taylor's stability, Ns (Steward et al. 2011; Taylor 1937), with retrogression distance. Demers et al. (2014) considered ancient landslide scars and historical failures from Eastern Canada, plotted in Fig. 3b, which shows widespread scatter, with some failures occurring with an Ns lower than 4 , and vastly different retrogression distances observed with the same Ns magnitude. However, a multitude of constraints that may affect landslide mobility are not accounted for in this database of field cases. The mechanisms of historical failures are not specified, with flowslides and lateral spreads being grouped together when the development of these two failures is fundamentally different. The rise of a valley wall or a rapid watercourse may hinder or aid the transport of failed material (e.g., Geertsema and L'Heureux 2014). Geometric constraints, such as the slope angle or upslope features, may signify increased shear stresses in the slope and a heightened mobility for failed material to vacate the backscarp. Rheological properties such as the remolded strength, or the remolded index proposed by Tavenas et al. (1983), will affect the ease by which soil is remolded by the slope movement. Developing a framework for how to relate retrogressive distance, $R$, and stability number, Ns, that considers additional constraints would allow for more refined preliminary calculations.

As an alternative to empirical correlations, modelling techniques can be employed to simulate a slope movement. Limit equilibrium methods are normally limited to only being able to consider the pre- or post-failure geometry and factor of safety, while large-deformation modelling may be warranted to consider softening behavior, or to locate a potentially predefined failure surface. Quinn et al. (2011b) showed that utilizing the peak strength of a material will likely overestimate the factor of safety for a sensitive clay slope movement, while a laboratory-determined remolded strength may provide a far lower bound. In addition, there are varying opinions on the definition and applicability of laboratory-measured remolded or residual strengths (e.g., Devenny 1975; Chaney and Richardson 1988). Recent hazard identification guidelines designate a retrogression distance of 15 times the slope height, but this relationship would not be conservative enough for several past failures (e.g., L'Heureux 2012). L'Heureux also noted that existing hazard guidelines do not consider the retrogression potential and material run-out capabilities. Therefore, it is desirable to investigate further the effect of site-specific soil 
Fig. 2. (a) Schematic of upward progressive failure mechanism proposed by Locat et al. (2011) where horizontal shear zone propagates into homogeneous material, after which $(b)$ overlying soil mass is mobilized into series of horst and graben structures that migrate downslope over more extensively remolded clay material.

\section{a) Shear Zone Propagation (Progressive Failure)}

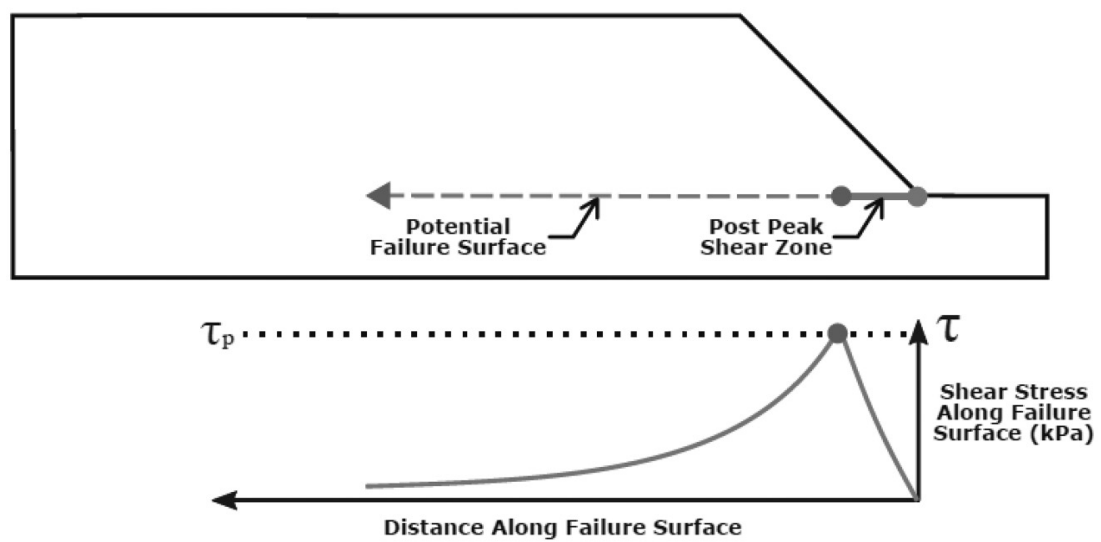

b) Lateral Spread Failure Morphology

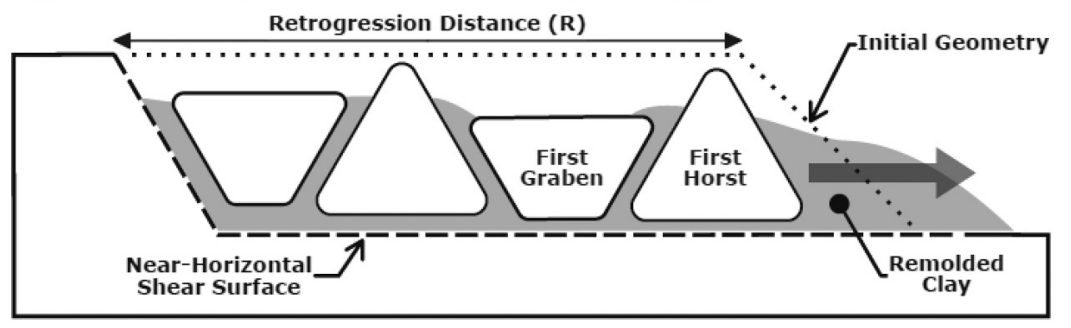

properties and geometric characteristics has on retrogression distance.

Field data relating stability number with observed retrogression distance show considerable scatter, whereas physical modelling practices allow for well-defined experiments to isolate particular variables for consideration. Park and Kutter (2015) recently demonstrated the successful use of artificially cemented materials in a physical model experiment, with samples of a broad range of strengths and sensitivities being subjected to dynamic stresses in a geotechnical centrifuge. In Kennedy et al. (2020), an artificially sensitive material with bespoke undrained shear strength was created with a combination of Speswhite kaolin clay and type 3 Portland cement. This material and the opportunity to use a large geotechnical centrifuge at C-CORE in Newfoundland, Canada, allow for the opportunity to investigate the effect of stability number and slope geometry on retrogression distance utilizing physical modelling.

Although retrogressive landslides pose a significant hazard, understanding is limited due to practical limitations of prefailure or post-failure investigations with implications to both empirical correlations and numerical modelling efforts. Physical modelling provides the opportunity to perform repeatable experiments with controlled boundary conditions, material properties, and failure triggering. The new soil-cement material gives the capability to create retrogressive landslide models with defined strength characteristics and defined geometry. The objectives of this study are to perform novel centrifuge models to directly observe retrogressive landslides, utilize the unique opportunity to observe the cross-sectional geometry of multiepisodic retrogressive landslide experiments to perform stability analysis, and explore the relationship between retrogression distance and published relationships for Taylor's stability number and large deformation shear strength.

\section{Experimental design and workflow}

\section{Centrifuge model design}

The centrifuge models were aimed at representing aspects of a typical retrogressive slope movement, in which a slope failure occurs, and the failed soil material remolds to such a degree that it flows away from the backscarp (e.g., Geertsema and L'Heureux 2014). Illustrated in Fig. 1, the initial failure unloads the toe of the slope and leads to successive retrogressive instabilities. In the field, this initial slide may be triggered by natural processes, such as river erosion (e.g., Lebuis et al. 1983) or an increase in pore pressure due to rainfall or snowmelt. Human factors, such as pile driving or surcharge loading due to construction processes, may also cause a disturbance and promote a slope movement. Figure 4 is a sideview of the centrifuge model experiments. The focus of the centrifuge experiments was on observing undrained sequential retrogressive slope movements that follow a sudden instability. Rather than attempt to model both an initial failure and have conditions favorable for retrogression to occur, a release door was implemented to simulate an initial failure through rapid loss of lateral support. Use of a release door provided a consistent initial failure from which to examine retrogressive landslide behavior.

Physical modelling of landslides in a geotechnical centrifuge is well versed in the literature (e.g., Schofield 1980; Kutter and James 1989; Madabhushi 2015). The concept of centrifuge modelling involves a small-scale model experiencing an inertial radial acceleration field greater than gravity by a factor of $N$. Scaling laws stem from the assumption that the stress level in the prototype model is the same as the stress level in the centrifuge model (e.g., Garnier 2007). Radial acceleration is defined as angular velocity multiplied by the radius squared, indicating that $N$ varies across the model depth (e.g., Schofield 1980). The $5.5 \mathrm{~m}$ radius geotechnical centrifuge at C-CORE in St. John's, Newfoundland, was used for 
Fig. 3. Two relationships for retrogression distance and stability number, Ns: (a) Mitchell and Markell (1974) and (b) Demers et al. (2014).
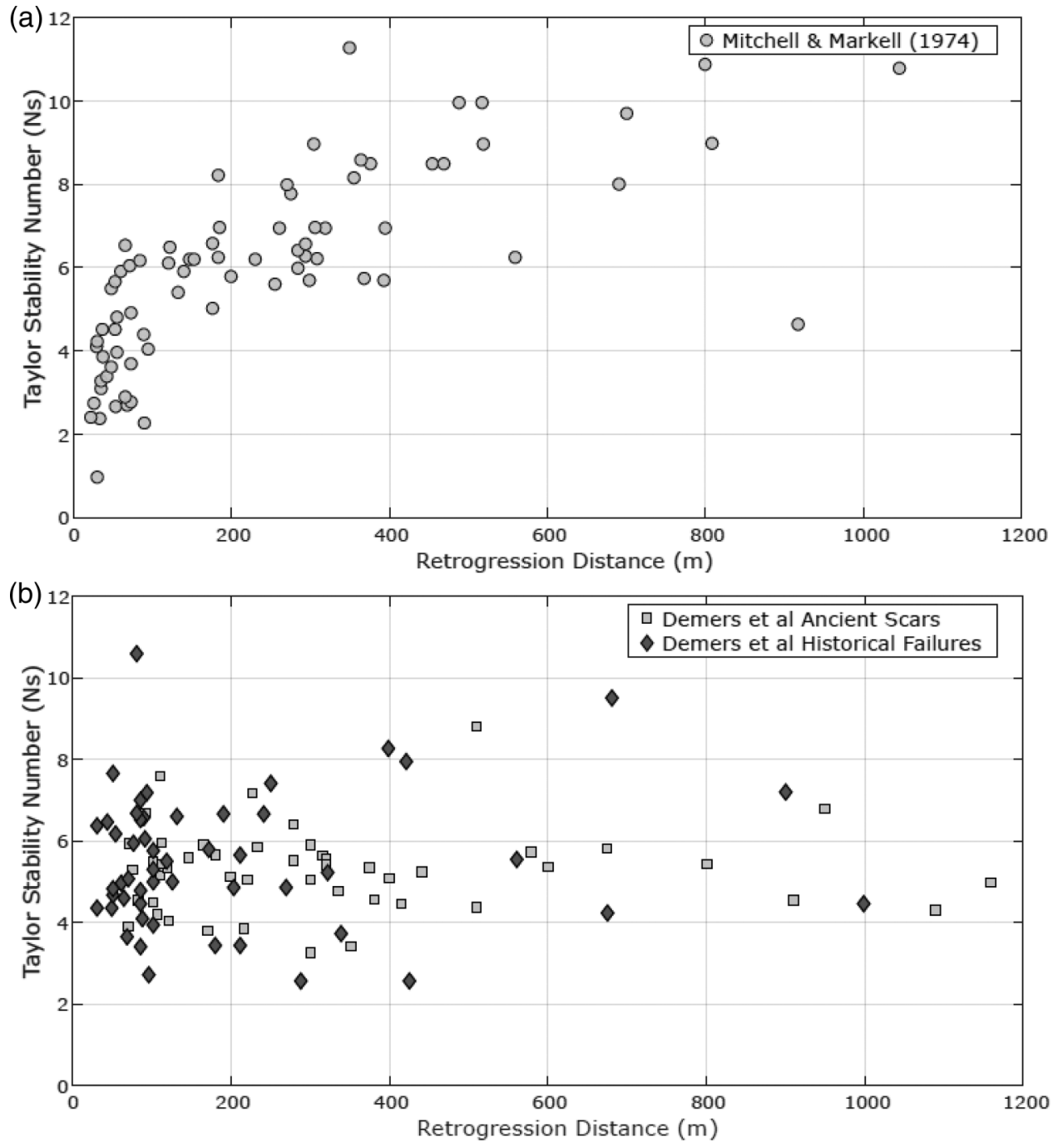

testing. The large-radius centrifuge reduces variable acceleration field across the height of the models $(150 \mathrm{~mm})$. The general centrifuge experiment convention of specifying the intended magnitude of $N$ at one-third of the slope height was adopted for this testing. All centrifuge tests were conducted with a target $N$ magnitude of 80 and model height of $150 \mathrm{~mm}$, resulting in a prototype height of $12 \mathrm{~m}$. Tests were performed as quickly as possible while following safety protocols, to simulate undrained conditions.

The experimental setup at C-CORE is a large rectangular strong box to contain all necessary components on the centrifuge arm. Figure 4 illustrates the various components of the experiment, which are placed within the strong box. Glass sidewalls supported by an aluminum frame, one on either side of the experiment, provided a transparent medium through which to capture digital photographs and a smooth surface to reduce sidewall effects. A $150 \mathrm{~mm} \times 638 \mathrm{~mm} \times 300 \mathrm{~mm}$ block of soil was placed on top of the aluminum base, with both items situated on a wooden riser. The aluminum base plate was lined with poly sheeting to prevent the soil from bonding to the aluminum during curing. The soil block was supported at the back by a fixed aluminum plate. The front of the slope was held in place by an aluminum door supported laterally by a vertically oriented actuator. This door was fitted with a counterweight on the opposite side, and a freely rotating hinge at the base, so that the release of the actuator would result in a rapid removal of lateral support to the soil block. Two cameras, referred to as camera 1 and camera 2 , were used to capture the experiment. The experiment consisted of incrementally raising the $g$ level up to $80 \mathrm{~g}$, releasing the door using the actuator, and observing slope movements with the two cameras.

\section{Materials and model preparation}

An artificially sensitive material was utilized in the physical models, which consisted of Speswhite kaolin clay (ISO 2004) mixed with Portland type 3 cement and water. Following mixing, hydration reactions form cement bonds to create a high void ratio, metastable soil structure at high moisture content with high sensitivity ( $\mathrm{St}>10$ for the mixture used in these experiments). Kennedy et al. (2020) include further details on material preparation, typical shear strength, and sensitivity gain with time, as well as effects of cement type, and cement to water content ratio for two types of clay as well as T1 and T3 cement types. They also reported peak and remolded strengths of those kaolin-cement mixtures with a range of water and cement contents, thus allowing the material's peak and remolded shear strength values to be defined as a function of time following mixing. A repeatable, stable, and high sensitivity mixture with peak strength of 20 to $30 \mathrm{kPa}$ is ideal for the retrogressive landslide experiments. The selected mixture contained $12 \%$ cement, defined as a ratio of the 
Fig. 4. Experimental setup in which block of cast sensitive clay is accelerated in centrifuge to apply elevated gravity environment followed by initiation of failure by rapid support of retaining door.

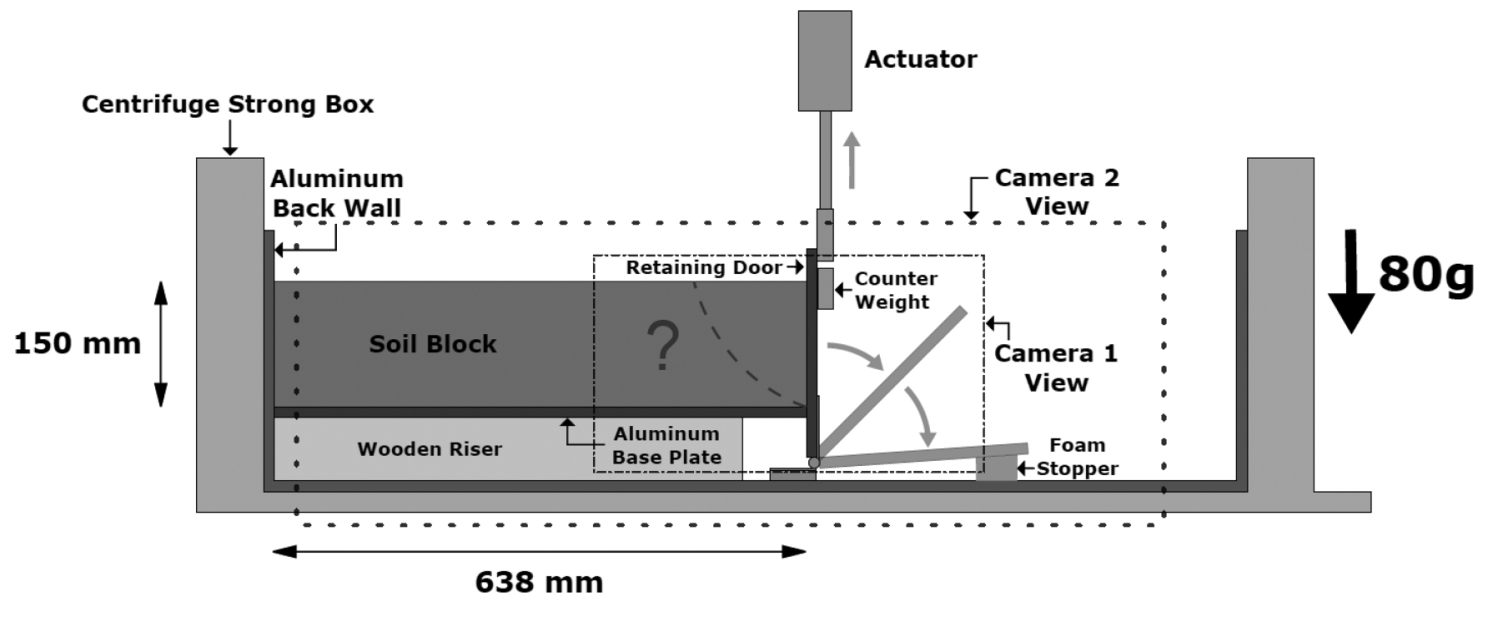

mass of cement to the mass of dry kaolin, and was prepared at an effective water content of $107 \%$, defined as the ratio of mass of water to the mass of soil and cement. The unit weight of this material was $13.8 \mathrm{kN} / \mathrm{m}^{3}$, approximately $2 \mathrm{kN} / \mathrm{m}^{3}$ lower than the Leda clay unit weights reported by Mayne (2014).

After identification of the material, an experimental workflow was created for retrogressive landslide experiments. Speswhite kaolin clay powder, from deposits in southwest England, was combined with a portion of the prescribed water in a large horizontal drum mixer. The kaolin-water combination was mixed for $2 \mathrm{~h}$, while under vacuum to reduce entrapped air. The required mass of kaolin-water material was then removed from the drum and combined with a cement slurry prepared with the remaining mass of water. The final mixture was mixed until a uniform paste was obtained, with care to not exceed $15 \mathrm{~min}$ and potentially disturb the produced cement bonds (e.g., Sasanian and Newson 2014). The material for each centrifuge experiment was then placed into plywood formwork, as well as four glass jars used to measure shear strength during curing. The plywood formwork, an example of which is shown in Fig. 5, was constructed around the poly-coated aluminum base plates and equipped with a non-stick paint. Both the block and jar samples were wrapped with plastic wrap to prevent moisture loss. The soil block was cast with an extra $25 \mathrm{~mm}$ of material (initial height = $175 \mathrm{~mm}$ ) on top to prevent crust formation within the test block. The glass jar samples were periodically tested to record development of undrained peak and remolded strength gain using the laboratory shear vane (Chaney and Richardson 1988; ASTM standard D4648 / D4648M-16, ASTM 2016) and the Swedish fall cone (ISO 2004). The motorized laboratory vane used a $12.7 \mathrm{~mm}$ high by $12.7 \mathrm{~mm}$ diameter vane for all tests. All springs were calibrated prior to shear strength measurements. Undrained shear strength magnitudes were calculated from fall cone results using cone factors of 0.8 for the $30^{\circ}$ tip and 0.27 for the $60^{\circ}$ tip (ISO 2004). Kennedy et al. (2020) showed very good agreement between laboratory vane and fall cone strengths.

After a set duration of curing, the formwork was removed, and the block was wire-trimmed to the model height of $150 \mathrm{~mm}$. The sides of the sample were then sprinkled with black sand to add texture for image analyses. The sample was then covered to limit moisture loss and transported to the centrifuge chamber. After being carefully slid into place in the centrifuge box, the retaining door was secured against the sample. The test procedure consisted of incremental spin-up to $80 \mathrm{~g}$ with a few seconds pause at $10 \mathrm{~g}$ intervals to capture digital photos. Generally, spin-up to the maximum acceleration was performed in $10 \mathrm{~min}$. After
Fig. 5. Formwork for curing soil blocks highlighted by plastic sheeting lining base, while non-stick paint coating was on side forms.

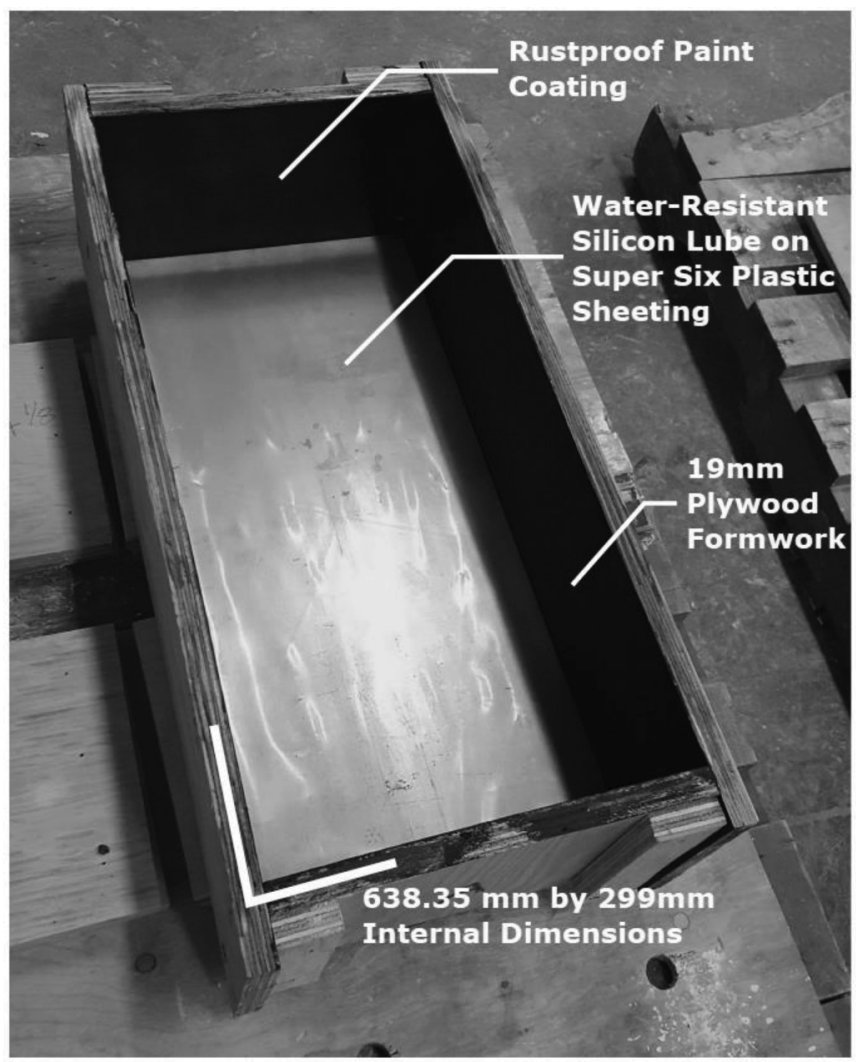

approximately $30 \mathrm{~s}$ at $80 \mathrm{~g}$, the door was released, and slope movements were recorded using two GoPro digital cameras. Spindown commenced after the slope movements ceased, with a duration of just under $10 \mathrm{~min}$. Post-failure samples were extracted with thin oedometer rings as soon as possible and the undrained shear strength of the failed material was determined using the Swedish fall cone.

\section{Results and discussion}

Presentation of the physical model results will be followed by stability analysis of incipient and retrogressive failures, and 
Fig. 6. Undrained shear strength of soil-cement mixture with curing time, measured on material not tested in centrifuge (i.e., jar and surficial block samples).

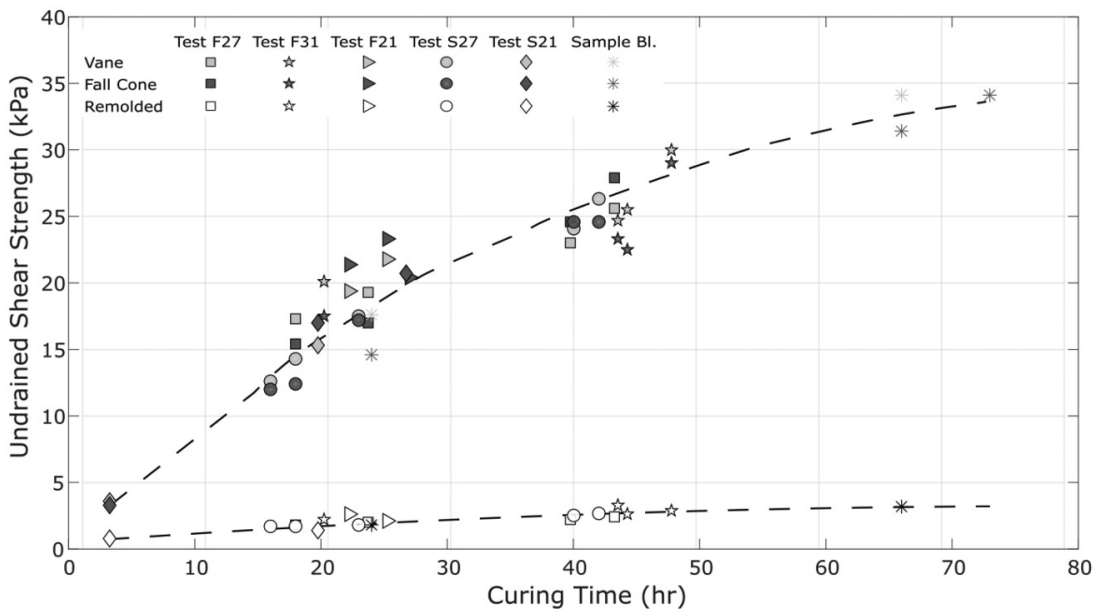

discussion on the relationship between Taylor's stability number and retrogression distance. For each physical model, undrained shear strength gain with curing time was measured in-sync with curing of the centrifuge test soil blocks. Centrifuge testing was recorded with two cameras, which provided digital time series for analysis of failure modes. Post-failure shear strength measurements were collected from the failure surface, remolded material, and intact material. Shear strength measurements and geometry extracted from the digital images provided the inputs for stability analyses to compare with failure modes observed in the centrifuge tests. Finally, the relationship between Taylor's stability number and retrogression distance was developed.

\section{Undrained strength development during curing}

Physical model testing was time sensitive due to the steadily increasing peak strength from 0-48 h (Fig. 6). Undrained peak and remolded strength gain with time is plotted in Fig. 6, which includes data from both jar samples and the upper crust of block samples (i.e., control samples created at the same time as the soil block). The observed strength gain exhibited non-linear strengthgain behavior over $72 \mathrm{~h}$ of curing time. Peak shear strength after a few hours of curing was $3 \mathrm{kPa}$, while the $24 \mathrm{~h}$ strength was close to $20 \mathrm{kPa}$, and the $72 \mathrm{~h}$ strength approached $35 \mathrm{kPa}$. The remolded shear strength after a few hours was $0.8 \mathrm{kPa}$, with that number increasing to $2.9 \mathrm{kPa}$ after $48 \mathrm{~h}$. Initially sensitivity was $4.4 \mathrm{a}$ few hours after curing and increased to approximately 7.5 after $16 \mathrm{~h}$, and then 9.5 or greater for all samples after $24 \mathrm{~h}$. Regular shear strength measurements during curing allowed for successful timing of physical model testing.

\section{Physical model results}

Results from a typical retrogressive landslide physical model, given in Fig. 7, consist of digital images captured during the experiment. These photographic records give the first available direct observations from a cross-sectional perspective of retrogressive landslide events. Experiments were typically completed in a few seconds after the door support was released. Camera footage from the centrifuge testing was converted to frames for image analysis of the failures. The control points, attached to the backside of the glass panel as black dots inside white outer rims, provided a series of stationary, known locations throughout the test sequences. The camera lens was a fish-eye lens and appears distorted, while the corrected geometry of the observed behavior was obtainable with image analysis. GeoPIV (White et al. 2003) was utilized to generate displacement vectors that are overlaid on digital images for visualization purposes. Figs. 7-10 display incipient and retrogressive failures for each centrifuge experiment. Each test was conducted at $80 \mathrm{~g}$ of centrifuge acceleration. The time values displayed on the figures correspond to the time after door release.

Test F27 (flat surface and shear strength $=27 \mathrm{kPa}$, Fig. 7) was performed on a $27 \mathrm{kPa}$ shear strength soil sample and a flat top slope. The corresponding Taylor's stability number was 6.12. Frame-by-frame analysis of this test is shown in Fig. 7. An initial failure immediately followed the door release, with a $45^{\circ}$ inclined failure surface originating at the toe extending up to a tension crack. During spin-up, compliance of the strong box base plate led to creation of tension cracks in the upper portion of the soil block. This initial failure occurred within $0.20 \mathrm{~s}$ and movement of the failed material ceased after an additional $0.32 \mathrm{~s}$. The presence of this failed material may have acted as lateral support at the toe of the slope, stabilizing the backscarp. Retrogression distance (measured from the top right edge of the initial soil block to the top of the last failure scarp) was $144 \mathrm{~mm}$, which gives a ratio of retrogression distance to slope height, $R / H=0.96$. This retrogressive behavior was very similar to earlier retrogressive landslide test F31 (flat surface and shear strength $=31 \mathrm{kPa}$, reported in Kennedy et al. 2020), which had an Ns $=5.33$, retrogression distance of $105 \mathrm{~mm}$, and an $\mathrm{R} / \mathrm{H}$ of 0.70 .

To isolate the effect of increasing stability number on retrogression magnitude, test F21 (flat surface and shear strength = $21 \mathrm{kPa}$, Fig. 8) was constructed with the same geometry, but a lower $21 \mathrm{kPa}$ shear strength soil. This configuration corresponds to a stability number of 7.81. The initial failure (Fig. $8 b$ ) following door release was steeper than test F27, at $60^{\circ}$, and was followed by a $0.40 \mathrm{~s}$ period of very slight backscarp movement. A larger rotational failure occurred between the 0.45 and $0.70 \mathrm{~s}$ time frames (Fig. 8c), with slope movement ceasing after $1.25 \mathrm{~s}$ after door release. The downslope material provided lateral support at the toe of the slope, preventing the rotational movement from continuing. The total retrogression distance of this test was $195 \mathrm{~mm}$, with an $\mathrm{R} / \mathrm{H}$ of 1.30 .

To investigate the effect of a static shear stress, test S27 $\left(5^{\circ}\right.$ sloped surface and shear strength $=27 \mathrm{kPa}$, Fig. 9) was performed with the same material strength as test F27, and therefore the same stability number, but with a change to a $5^{\circ}$ slope angle. The increase in slope angle subsequently increased mobility of the failed material. Following door release the initial failure was a complex topple movement to a tension crack, with the resulting geometry holding for over $10 \mathrm{~s}$. At $10.8 \mathrm{~s}$, a large planar failure was observed (Fig. 9d), inclined at approximately $35^{\circ}$ from 
Fig. 7. F27 test series analysis (flat slope and shear strength $=27 \mathrm{kPa}$ ), with black vectors overlaid on soil block to highlight movement of failed block in first few hundredths of a second after door release. Vectors are projected from previous frame to current one.
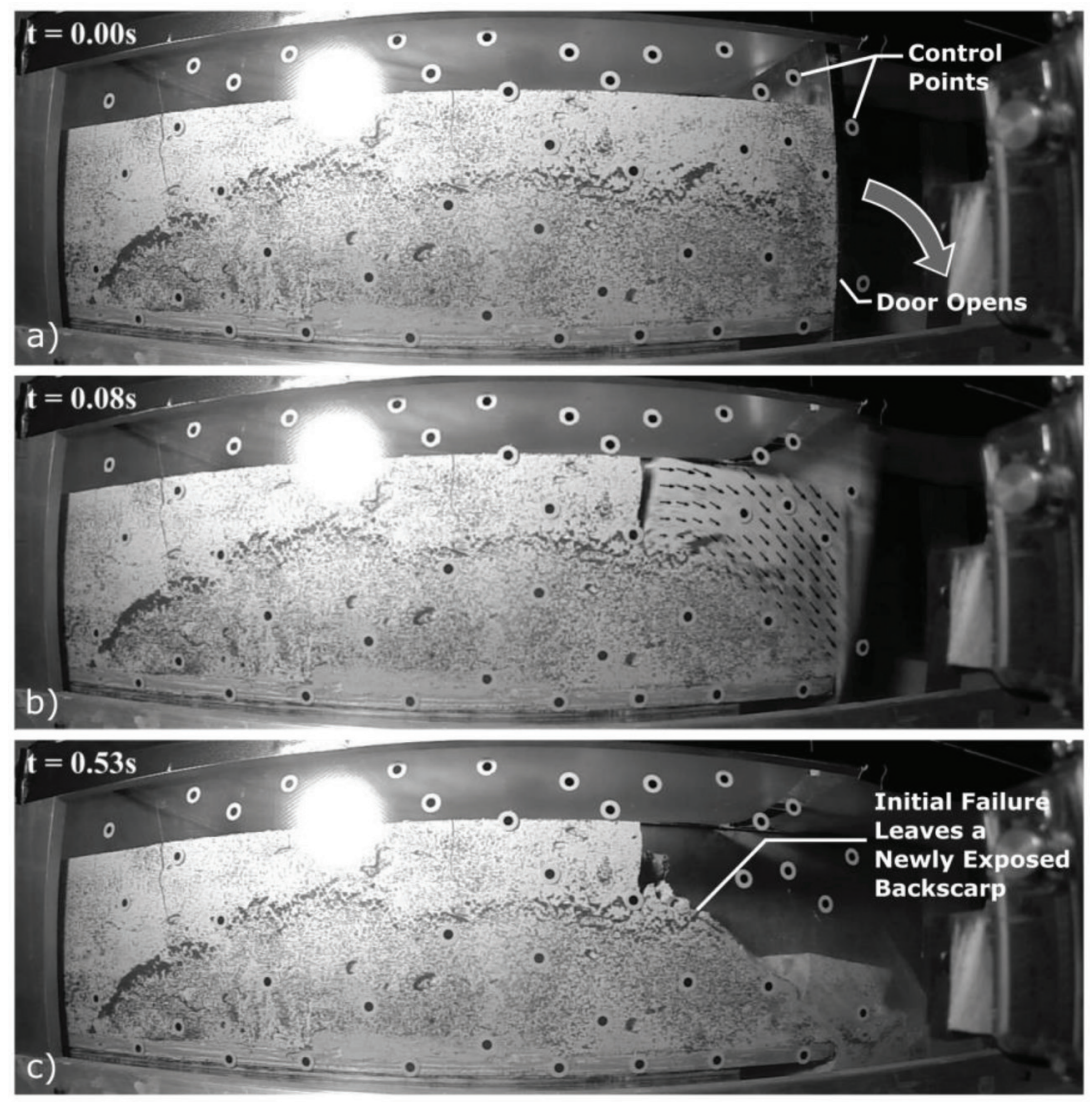

the horizontal to a tension crack. The failed material stabilized after less than $1 \mathrm{~s}$, migrating a third of the way down the slope. The total retrogression distance was $220 \mathrm{~mm}$, with an $\mathrm{R} / \mathrm{H}$ of 1.46 .

Finally, the last retrogressive landslide test examined the combined effects of lower shear strength and sloped surface. Test S21 $\left(5^{\circ}\right.$ sloped surface and shear strength $=21 \mathrm{kPa}$, Fig. 10) was performed as a replicated sample of test F21, with the same stability number of 7.81, but inclined at a $5^{\circ}$ slope. The initial failure following door release (Fig. 10b) was more extensive than previous tests and occurred within $0.1 \mathrm{~s}$. Complete vacancy of this material to the collection area (Fig. 10c) allowed for a secondary rotation failure that was rapid enough to migrate out of the failure zone as well. A third rotational movement (Fig. 10d) was observed after the second failure reduced lateral stability on the backscarp. This failure moved downslope for more than $0.5 \mathrm{~s}$, at which point a fourth failure followed (Fig. 10e). Geertsema and L'Heureux (2014) proposed that while a rupture surface sloping toward the bottom of the toe may assist with removal of the failed material, it may also limit retrogression by decreasing the backscarp height during the process of successive failures. The photographic record of test S21 shows consistent behavior with the rupture surface sloping upwards towards the surface. This final failure migrated downslope as the previous failures slowly slid along a shared shear plane, stabilizing after $2 \mathrm{~s}$ with the majority of the final two failures remaining in the failure bowl. The total retrogression distance of this multiple phase failure was $475 \mathrm{~mm}$, corresponding to an $R / H$ of 3.16 .

\section{Softening along shear plane during tests}

Material strength characterization is completed at regular intervals following mixing to ensure the material is accurately representing behavior of natural sensitive clays, gather pre-test shear strength information to assess softening along the shear plane, and for inputs in stability analysis. Baseline laboratory vane tests, performed shortly before centrifuge testing, were continued beyond the peak strength, to quantify shear strength degradation with continuing rotation. Following the physical model tests, fall cone testing was performed along the shear plane as well as within the intact and remolded material to quantify softening.

Baseline laboratory vane tests for F27 and S27, shown in Fig. 11, indicate consistent peak strength, strength degradation, and remolded strength values between mixture iterations as well as repeat tests. Peak shear strengths were reached after an average of $15^{\circ}$ of rotation. Shear strength decreased to less than $20 \%$ of the peak value after $360^{\circ}$ of rotation. The average sensitivity ratio for these tests was 10.3 , which is classified as extra-sensitive in the Canadian foundation engineering manual (Canadian Geotechnical Society 2013). Post-test shear strength measurements from F27 and S27 tests show the intact material incurred no loss of strength. However, measurements from the failed material recorded a reduction to $88 \%$ of the peak strength for test $\mathrm{F} 27$ and a reduction to $56 \%$ of the peak strength for test S27. Similar to Bernander (2000) and Dey et al. (2015), despite the magnitude of remolding that occurred during the retrogressive failures, (final configurations shown in Figs. $7 c$ and $9 e$ ) strengths remain more than $5-8 \times$ the laboratory-measured remolded value with the $5^{\circ}$ slope test exhibiting greater strength degradation.

Laboratory vane shear strength curves for test F21 are plotted in Fig. 12 along with post-test fall cone measurements for F21 and S21. Consistent repeat tests from F21 show the material exhibited brittle behavior similar to the F27 samples, with a reduction to 
Fig. 8. F21 test series analysis (flat slope and shear strength $=21 \mathrm{kPa}$ ), with black vectors overlaid on soil block to highlight initial door release failure, as well as rotational failure that followed removal of that material. Vectors are projected from previous frame to current one.
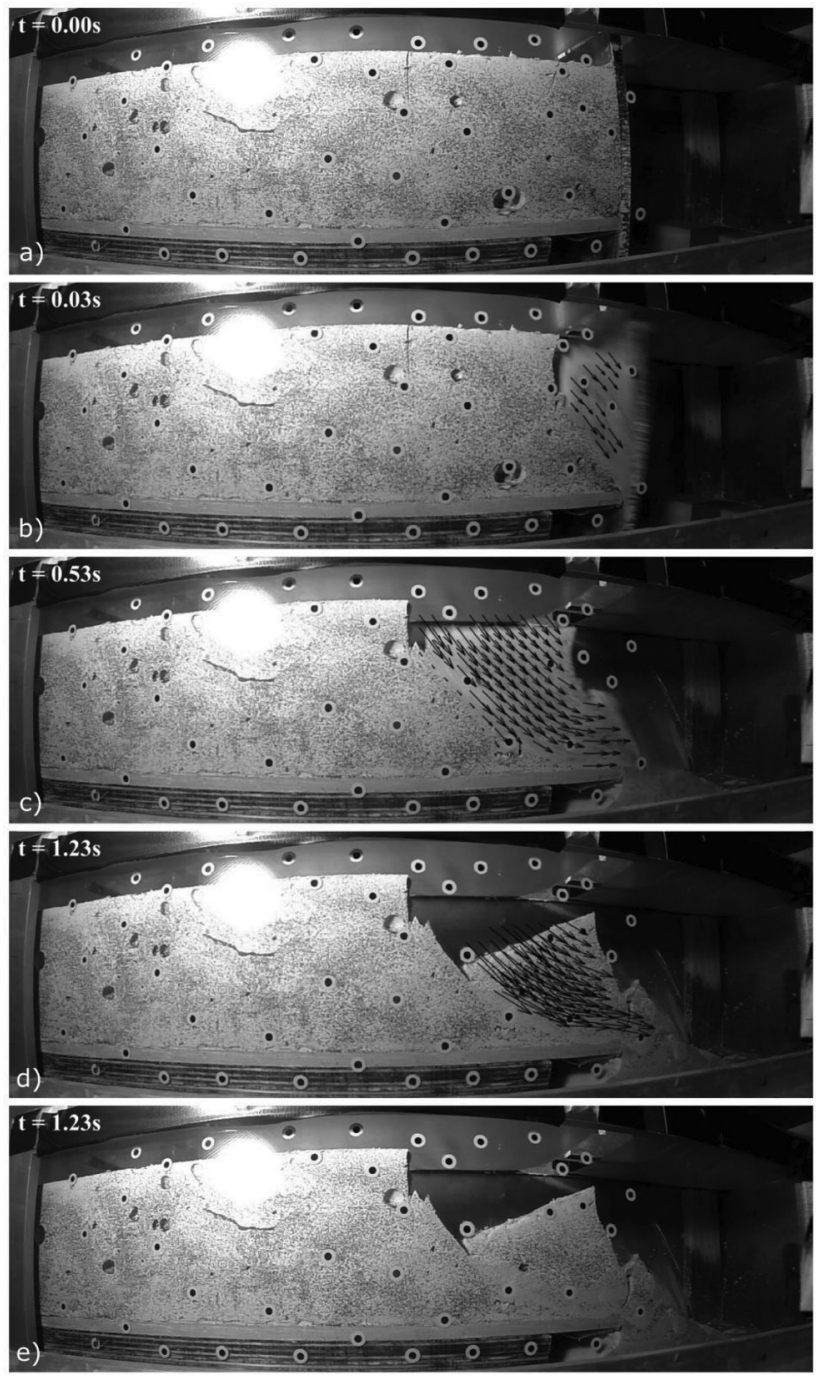

$20 \%$ of the peak strength after $360^{\circ}$ of rotation and to $9 \%$ after $1800^{\circ}$ of rotation. Average sensitivity for the test F21 material was 10.6. Post-failure samples from test F21 were obtained from the failed material proximal to the original slope toe, as well as from the intact soil block. The remolded material, taken from $X=30 \mathrm{~mm}$, showed a reduction to $72 \%$ of the peak shear strength. Samples from test S21 were taken from upslope material that experienced relatively little displacement, labelled as $X=-320 \mathrm{~mm}$, as well as two locations downslope in the failed material to compare to the flat case. Samples on the debris proximal to the original slope toe and on further downslope material exhibited a resistance equal to $58 \%$ and $47 \%$ of the peak strength, respectively. The $X=$ $-320 \mathrm{~mm}$ sample possessed a shear strength equal to $78 \%$ of the peak strength. Even in the most extreme case of the S21 test at $X=400 \mathrm{~mm}$, the peak strength of $10 \mathrm{kPa}$ is more than $4 \times$ the laboratory-measured remolded strength. These results indicate, similar to what Bernander (2000) and Dey et al. (2015) found in numerical modelling efforts, that the laboratory-measured remolded strength is not mobilized in the resultant spoil of a
Fig. 9. S27 test series analysis $\left(5^{\circ}\right.$ slope and shear strength $\left.=27 \mathrm{kPa}\right)$, with black vectors overlaid on soil block to highlight initial door release failure, as well as failure that followed removal of that material after notable pause. Vectors are projected from previous frame to current one.
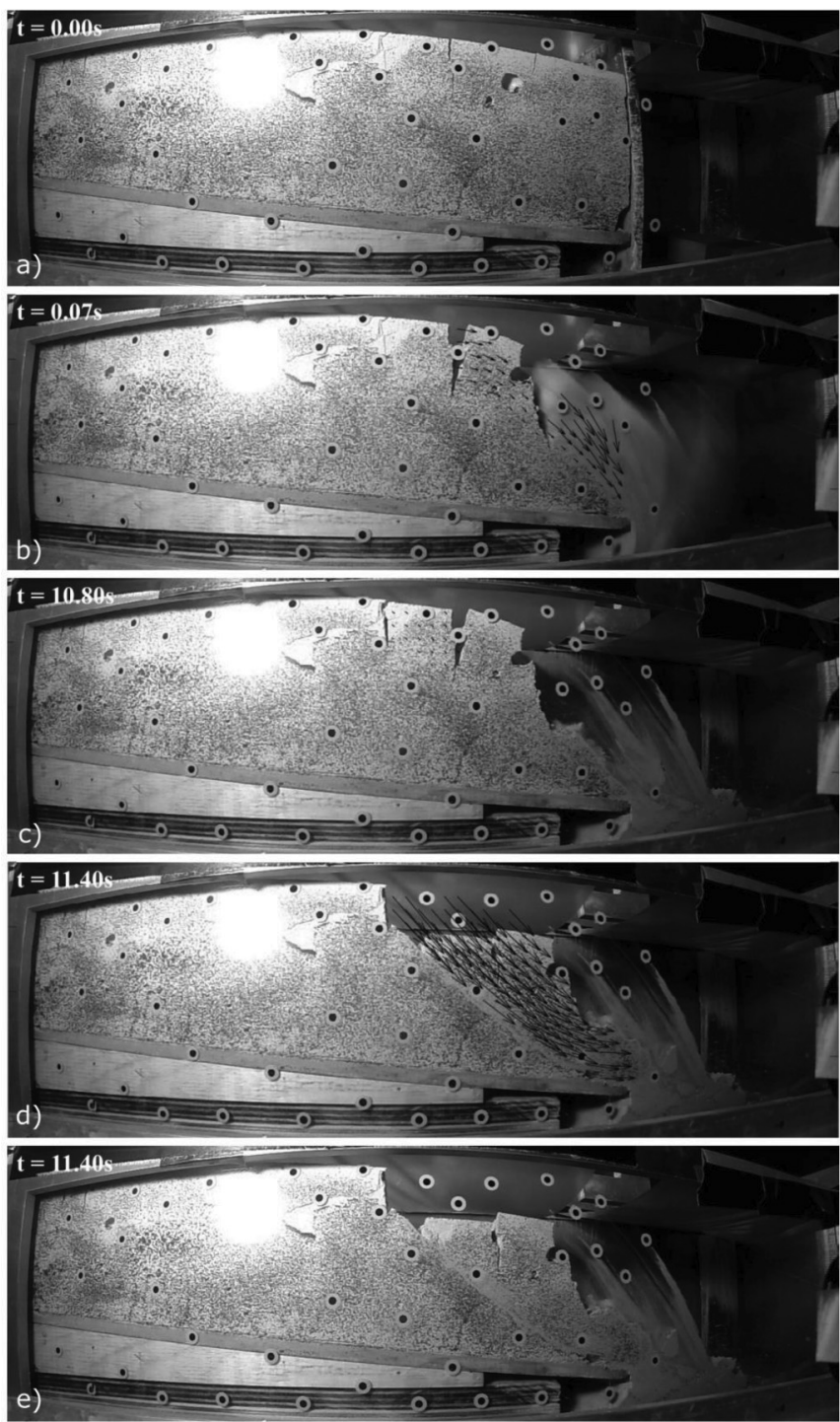

retrogressive landslide test. Although this may be a result of the inability to test the shear strength of a very thin shear band or due to the nature of the physical models, further examination is warranted in future experiments.

\section{Stability analyses of retrogressive landslide episodes}

For this idealized test case the high-speed photographic time series allows for more thorough analysis of retrogressive landslide tests. Detailed visual and quantitative GeoPIV-aided assessment of the experiments (see Figs. 7-10 and two videos in the Supplementary Material ${ }^{1}$ ) shows that, in these experiments, retrogression occurred principally through distinct episodes. While numerical modelling capabilities of sensitive clay landslides continue to develop (e.g., Bernander 2000; Dey et al. 2015; Locat et al. 2015; Zhang et al. 2017, 2020; Tremblay-Auger et al. 2021), in this work the episodic nature of the retrogressive landslide 
Fig. 10. S21 test series analysis $\left(5^{\circ}\right.$ slope and shear strength $\left.=21 \mathrm{kPa}\right)$, with vectors overlaid on soil block to highlight initial door release failure, which was immediately followed by series of retrogressive failures. Vectors are projected from previous frame to current one.
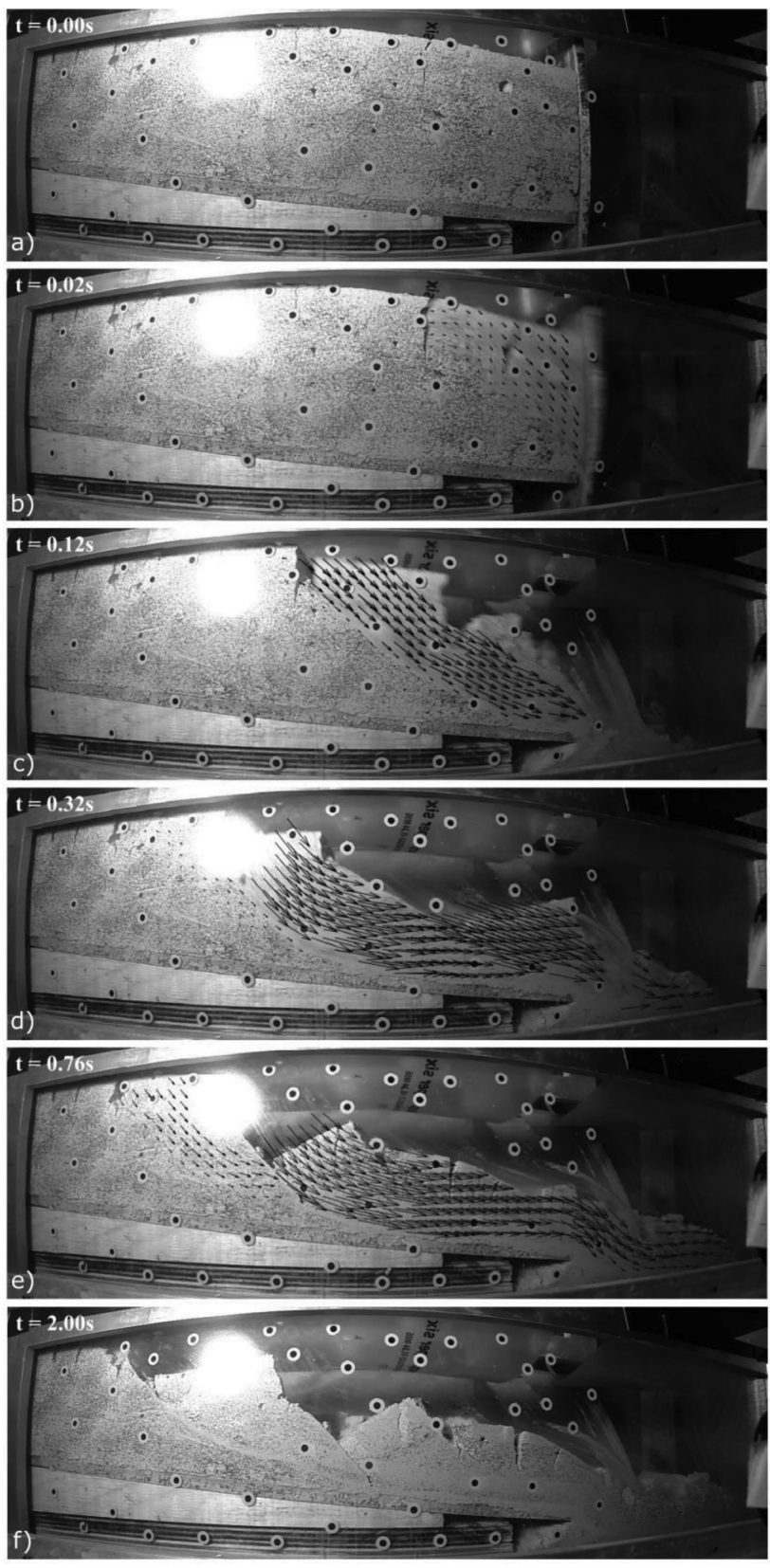

experiments permits a static analysis at discrete times. Thus, the limit equilibrium method is used to locate the kinematically admissible slip surface with the lowest factor of safety and compare with the physical models. To be clear, limit equilibrium analysis using undrained shear strength is not generally applicable for retrogressive landslides. For this unique and idealized case of episodic retrogression and having direct knowledge of landslide geometry every few hundredths of a second, these analyses and comparisons focussed on: (i) initiation of each sequential retrogressive episode and (ii) final geometry to assess potential for further retrogression. Cross-sectional geometries and locations of the failure surfaces were determined for each of the observed failure episodes using GeoPIV (White et al. 2003) and then scaled to prototype dimensions (using $N=80$ ). Limit equilibrium analyses were performed using SLOPE/W (GeoStudio 2018) with undrained strength material models (i.e., $\phi=0$ ) applied for all materials. Analyses for F21 and S21 are included in Figs. 13 and 14, respectively. The soil is assigned a unit weight $\left(\gamma=13.8 \mathrm{kN} / \mathrm{m}^{3}\right.$ in all cases) and cohesion associated with representative measurements before and after the centrifuge test (strength measurements are reported in Figs. 11 and 12). The underlying base was conceptualized as an impenetrable unit. A tension crack depth was specified for each phase, as identified from the camera footage. In Figs. 13 and 14, the observed failure surface is denoted with a black line, while the critical or analyzed slip surface is shown with a white line. The focus of these analyses was to investigate the ability of limit equilibrium to capture step-by-step episodes of a retrogressive landslide experiment if accurate geometry and representative strength distribution are known.

Analysis of test F21 episodes (Fig. 13) considered the initial failure following door release, second retrogressive episode, and then the final geometry. For the initial geometry (Fig. 13a), the analysis confirmed a factor of safety well below $1(\mathrm{FS}=0.411)$ as expected for the first episode due to rapid loss of lateral support from the door. Analysis of the second failure episode, Fig. 13b, shows the observed rotational failure that followed was geometrically similar to the surface from stability analysis. The low factor of safety in this instance is again attributed to the rapidity of the slope movement causing an unsupported face within only a few tenths of a second between the two failure episodes. Lastly, potential for further retrogression of the post-test geometry was investigated with two scenarios shown in Figs. $13 c$ and $13 d$. First, analysis is displayed in Fig. $13 c$ considering further movements along the observed failure surface, which was assigned the postfailure measured shear strength $(15.1 \mathrm{kPa})$. This produced a factor of safety slightly greater than 1 , which supports the observed ending of downslope movements at this geometry. Analysis for a subsequent retrogression episode, shown in Fig. 13d, found the critical slip surface with an intact strength assigned to the main soil block and post-test strength assigned to the failed material. This analysis found that a shallow upslope movement may have been very close to failing, with a factor of safety of 0.99 . For this unique case that incorporated extensive geometric and strength data, limit equilibrium provided a reasonable estimation of the observed failure geometry (white lines and black lines are similar in Fig. 13) and the calculated safety factors are consistent with physical results.

In test $\mathrm{S} 21$, the addition of a $5^{\circ}$ slope angle was accompanied by multiple retrogressive stages, the analyses of which are shown in Fig. 14. The initial and secondary failure episodes occurred in intact material and exited the experiment immediately after door release. Thus, intact strength was applied to the entire model in Figs. 14a and 14b. The critical slip surfaces agree with the observed failures and the factors of safety were well below 1.0, which agrees with the observed physical results. Although significantly greater total retrogression distance occurred in S21, only a nominal decrease in initial safety factor is determined (0.401 in S21 versus 0.411 in F21). Analysis of the third and fourth episodes (Figs. 14c and 14d) assigned intact strength to the soil block and post-test measured shear strength to the failed material. Analyses showed factors of safety between $0.92-0.97$ suggesting movements would occur. Critical slip surfaces were again observed to be representative of the observed failure stage geometries. For the final geometry stability analyses were anticipated to determine a safety factor above 1.0. Two scenarios were analysed based on the representative post-test measured shear strengths. In Fig. $14 e$, cohesion $=16.5 \mathrm{kPa}$ (measured at $X=-320 \mathrm{~mm}$ ) was assigned to the failed material, while in Fig. $14 f$ cohesion $=$ $9.9 \mathrm{kPa}$ (measured at $X=400 \mathrm{~mm}$ ) was used. The critical failure surfaces indicated in Figs. 14e and $14 f$ indicate that a shear strength of $16.5 \mathrm{kPa}$ in the failed material resulted in a factor of safety greater 
Fig. 11. Shear strength versus rotation measured with miniature laboratory vane along with post-test measured shear strengths from F27 and S27 tests quantifying degree of remolding during retrogressive landslide experiments. [Color online.]

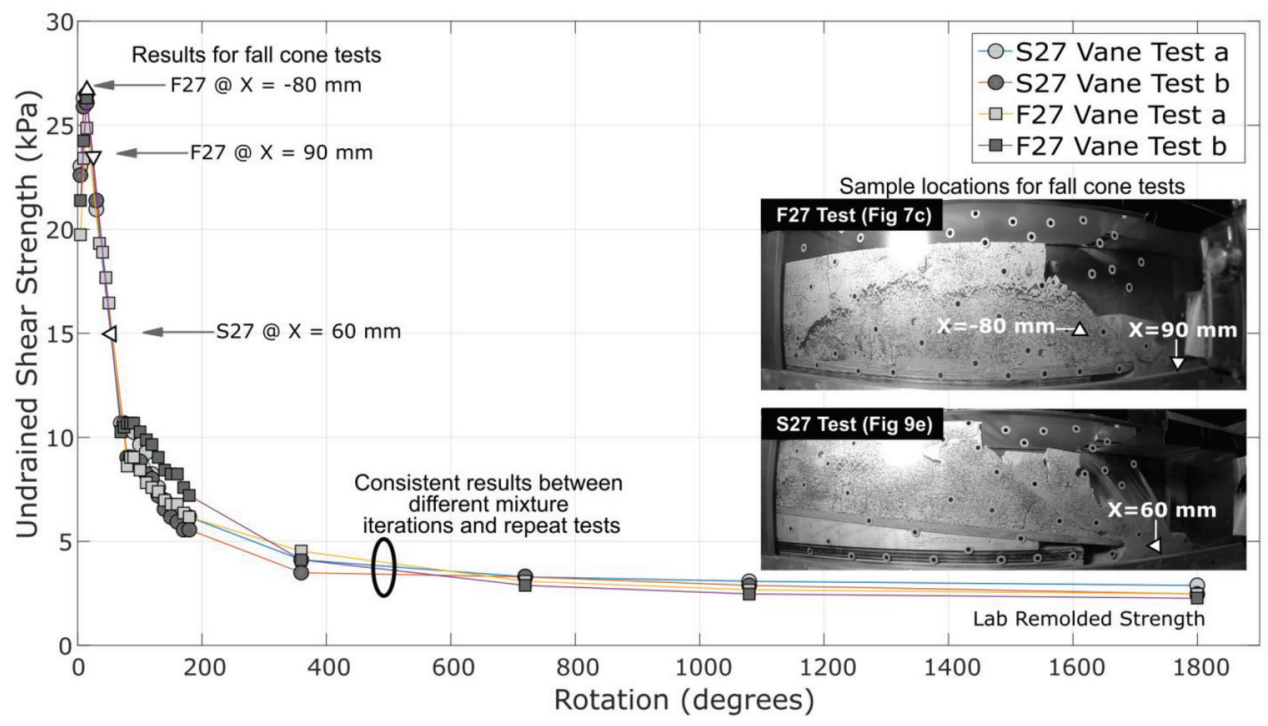

Fig. 12. Shear strength versus rotation measured with miniature laboratory vane along with post-test measured shear strengths from $21 \mathrm{kPa}$ physical model tests quantifying degree of remolding during retrogressive landslide experiments. [Color online.]

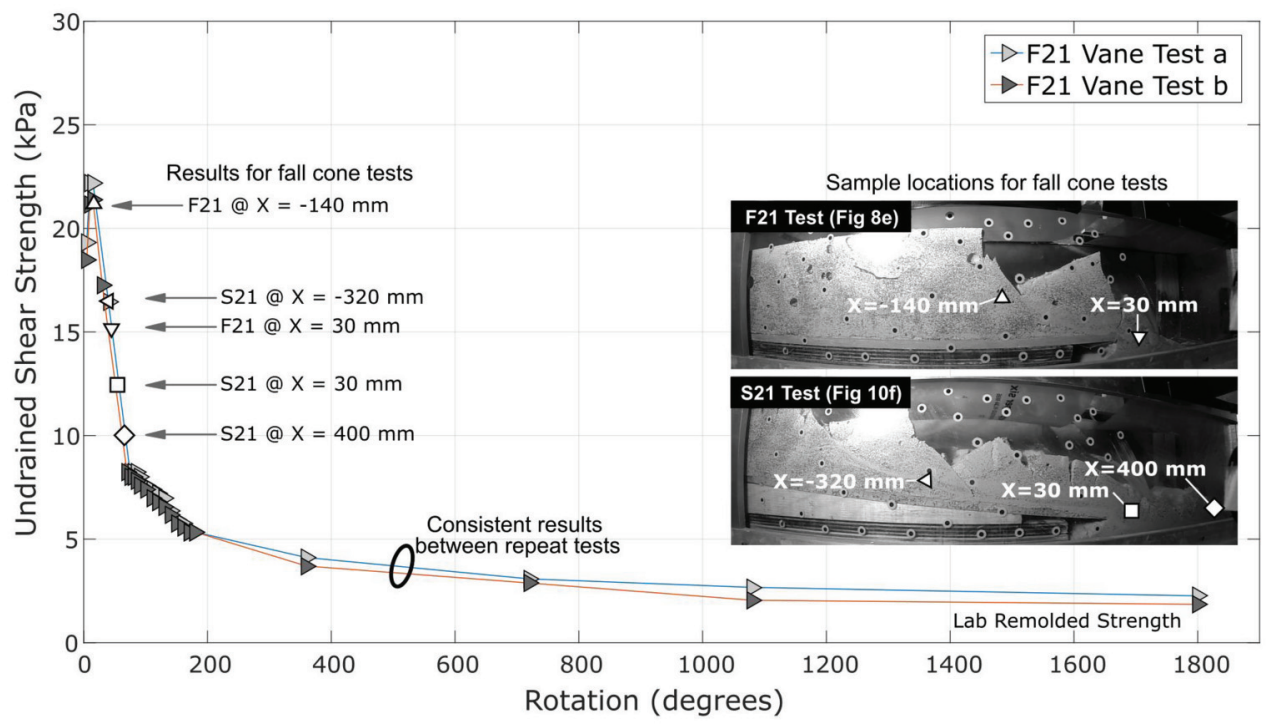

than 1. Utilizing the lowest post-test strength of $9.9 \mathrm{kPa}$, stability analysis showed that an additional failure could have occurred if the strength measured in the debris is applied. The measurements and analyses suggest that the average shear strength of the failed material is between 16.5 and $9.9 \mathrm{kPa}$ and is spatially distributed along the failure surface. In all cases shown in Fig. 14, there is remarkable agreement in the geometry and safety factors determined from limit equilibrium analysis compared with the physical models.

\section{Quantification of retrogression distance in context of published relationships}

The observed retrogression distance from the five centrifuge experiments (four reported in detail here and one in Kennedy et al. 2020) are explored quantitatively within the context of semi-empirical relationships reported in the literature in Fig. 15. The first framework, illustrated in Fig. 15a, uses the stability number, Ns, from an undrained slope stability analyses as a representative measure of the potential energy driving retrogression following Mitchell and Markell (1974, Fig. 3a) and further explored by Demers et al. (2014, Fig. 3b). In this figure, retrogression distance $(R)$ is defined as the horizontal distance from the crest of the original slope, to the scarp of the post-failure slope, and then converted to prototype-scale. For context, according to Taylor's stability charts, a stability number of $\sim 4$ would have a safety factor equal to unity for a $90^{\circ}$ slope. All tests were conducted at stability numbers greater than this value to ensure the occurrence of failure. While the idealized boundary conditions for triggering (e.g., database of experiments contains only sequential retrogression failures, excluding flows and lateral spreads) and the inherent limitations of physical modelling in terms of length scale for remolding, these five experiments permit a unique opportunity to isolate the sensitivity of retrogression to one variable - the ability of the debris to exit the failure 
Fig. 13. Limit equilibrium stability analyses of F21 test series (flat slope and $21 \mathrm{kPa}$ shear strength) for (a) initial failure episode, (b) second episode, $(c)$ potential for further retrogression along observed failure surface, and $(d)$ potential for subsequent retrogression episode.

\section{F21 Test}

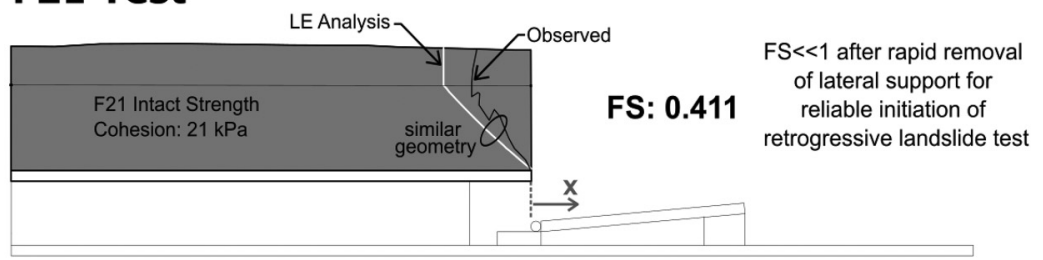

a) First episode $(t=0.00 \mathrm{~s})$

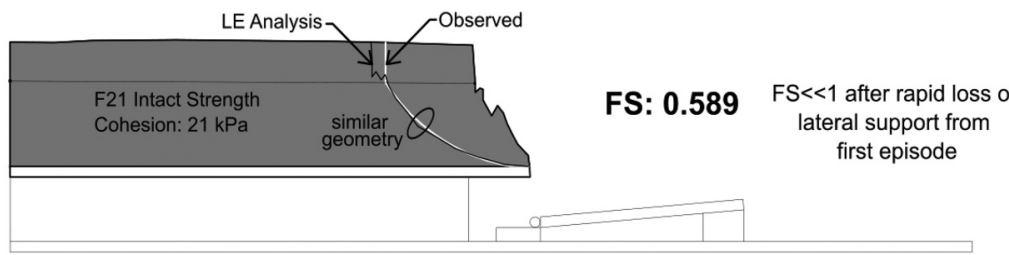

b) Second episode $(t=0.13 s)$

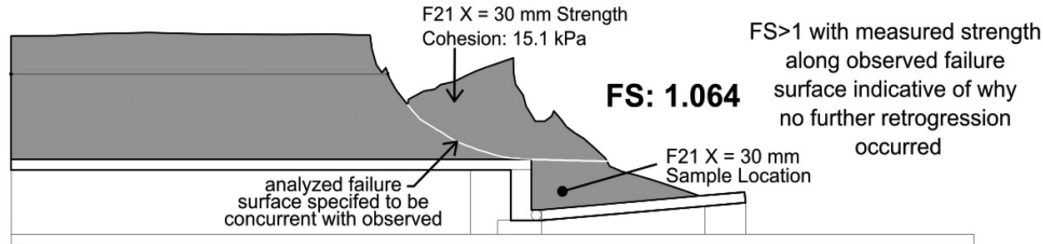

c) Potential for further retrogression along observed failure surface

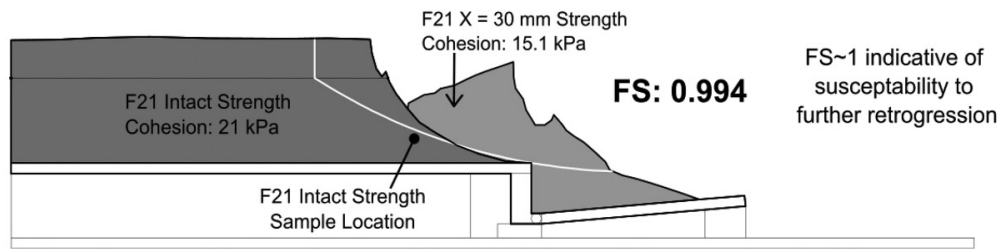

d) Potential for further retrogression using spatially representative strengths

bowl, as controlled in the experiment by an imposed $5^{\circ}$ slope, albeit under highly idealized conditions.

We first consider the retrogression distance observed in the three flat physical models. As expected following the work of Mitchell and Markell (1974), a higher stability number correlates with an increase in retrogression distance. However, the addition of a $5^{\circ}$ slope angle, which had a nominal decrease on the initial safety factor of the block, was sufficient to ensure more debris left the failure bowl, and correspondingly increased the retrogression distance by more than double compared with the flat case conducted at the same stability number. These observations serve to illustrate that despite stability number and retrogression distance being highly correlated for a given slope geometry, stability number alone is an insufficient measure from which to predict retrogression distance without considerable uncertainty.

Mindful that the majority of sensitive clay landslides are triggered under an effective stress path forced by pore pressure changes following combinations of snowmelt or rainfall infiltration, it could be argued that it is not entirely internally logically consistent to rely on a measure of stability from an undrained analysis of the original pre-failure geometry to predict retrogression distance. In an alternative framework, retrogression distance can be explored as a function of the degree of remolding of the debris, expressed as the undrained shear strength achieved by the debris ranging from peak to fully remolded. As shown in Figs. 11 and 12, considerable shear displacement (vane rotation) of the artificial sensitive clay is required to achieve its fully remolded undrained strength similar to natural sensitive materials. In their numerical analyses of the 1994 landslide at SainteMonique, Quebec, Locat et al. (2015) explored the sensitivity of retrogression distance calculated through numerical modelling of progressive failure to the large deformation undrained strength. Their results indicate that the relationship between retrogression distance and large deformation shear strength is non-linear, with retrogression distance increasing asymptotically as the shear strength of the debris approaches the fully remolded value. In Fig. 15b, we explore the observed retrogression distance in our experiments and the observed degree of remolding on these same axes. The resulting relationship from the experimental data exhibits the same non-linear shape as that of Locat et al. (2015), illustrating the sensitivity of retrogression distance to factors, such as slope angle explored in this study, to the degree of remolding achieved by the landslide debris. Finally, it should be reiterated that the data presented here are for highly idealized experiments for the sake of isolation of variables through comparison between tests. The authors do not propose that these specific relationships apply to field conditions. 
Fig. 14. Limit equilibrium stability analyses for each stage of S21 test series $\left(5^{\circ}\right.$ slope and $21 \mathrm{kPa}$ shear strength) for (a) first episode, (b) second episode, $(c)$ third episode, $(d)$ fourth episode, $(e)$ potential for further retrogression using shear strength measured on failure surface, and $(f)$ potential for further retrogression using shear strength of debris.

\section{S21 Test}

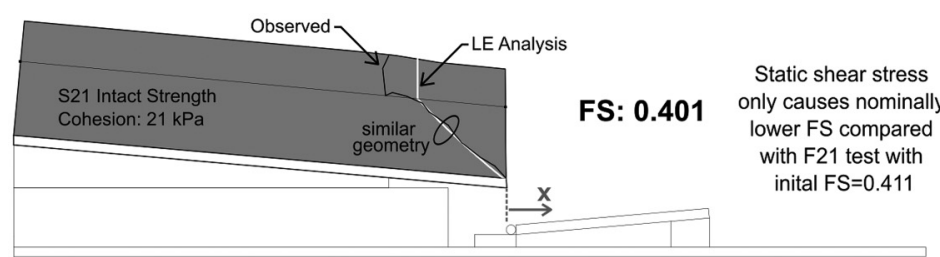

a) First episode $(t=0.00 \mathrm{~s})$

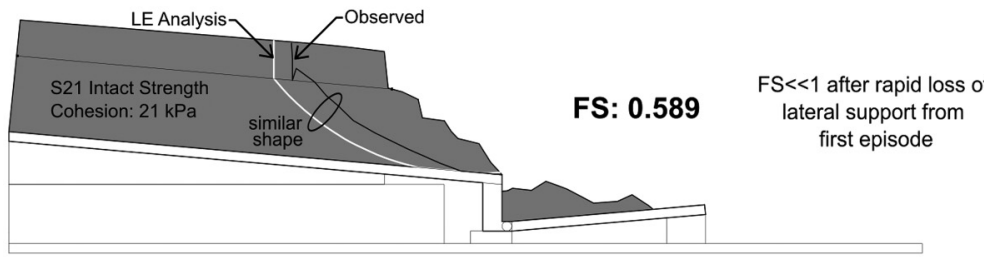

b) Second episode $(t=0.10 \mathrm{~s})$

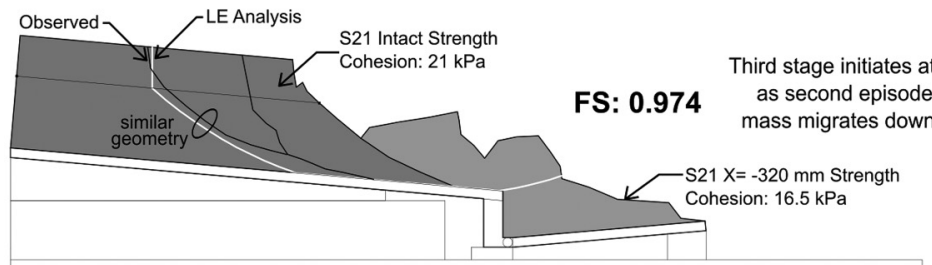

c) Third episode $(t=0.19 \mathrm{~s})$

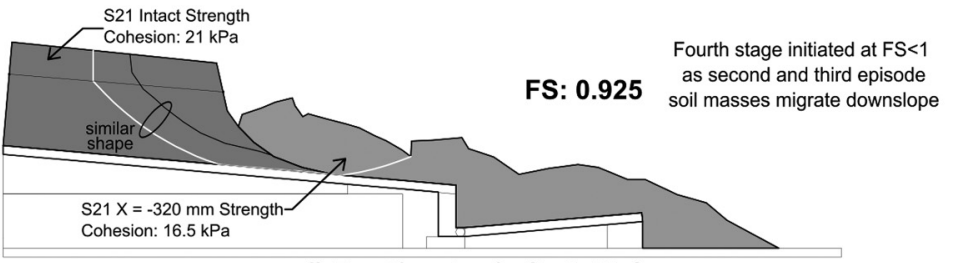

d) Fourth episode $(t=0.50 \mathrm{~s})$

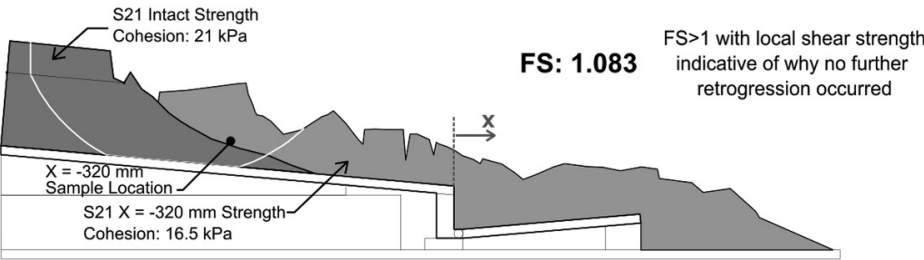

e) Potential for further retrogression using shear strength from failure plane

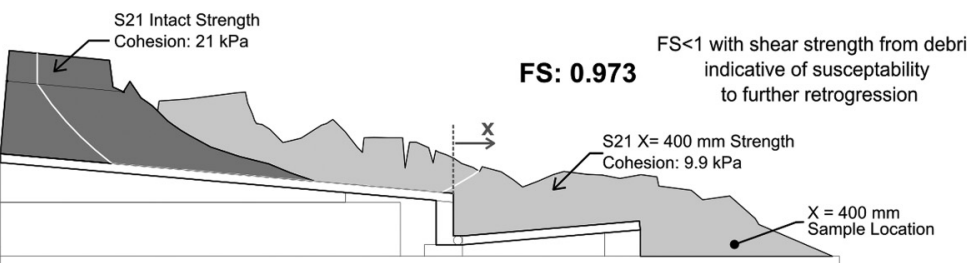

f) Potential for further retrogression using shear strength from debris 
Fig. 15. Quantification of observed retrogression distance with published relationships based on (a) Taylor's stability number and (b) large deformation shear strength attained by debris.
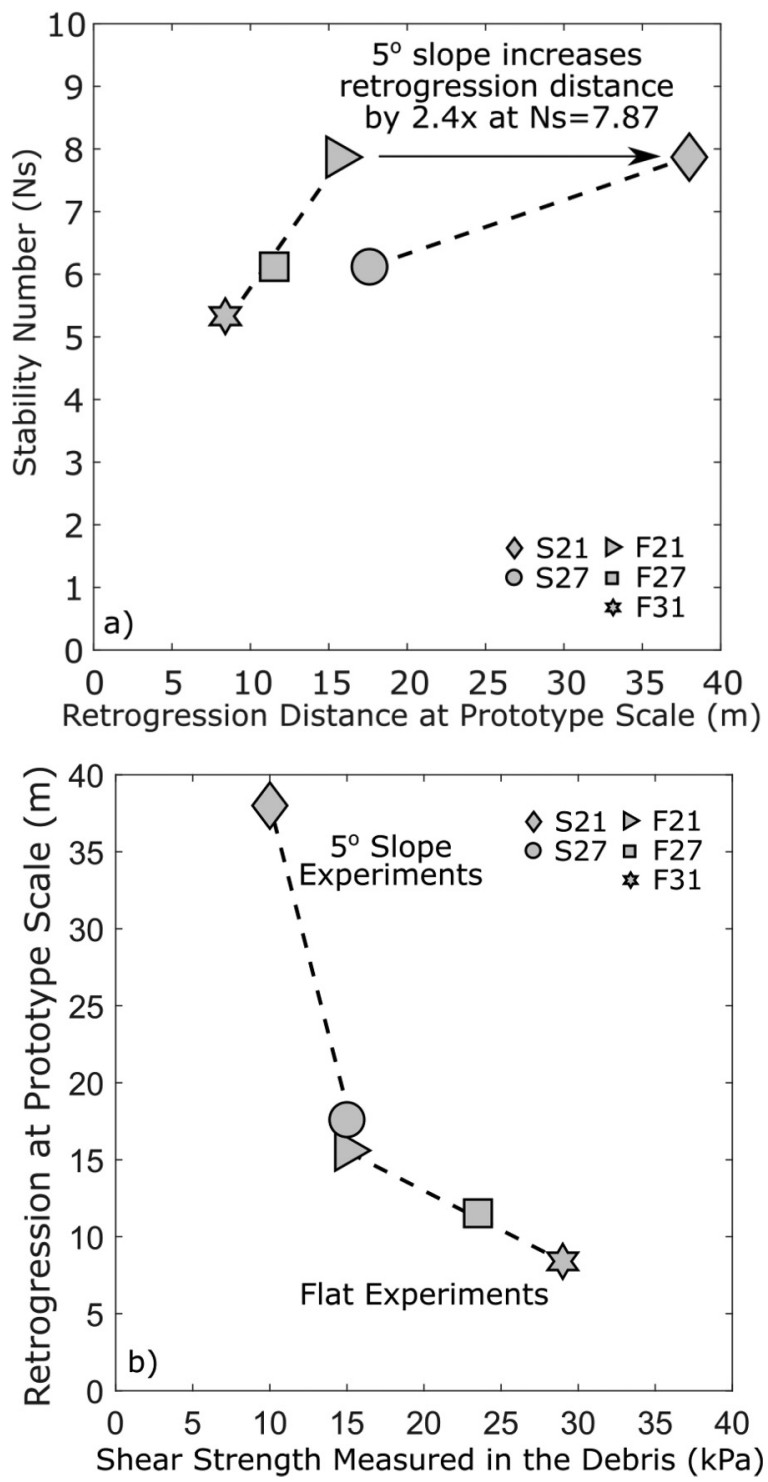

\section{Conclusions}

Establishing the maximal retrogression distance of a potentially unstable slope scenario is important for hazard identification in sensitive clay slopes in eastern Canada. Investigators may turn to the worst historical cases observed within the watershed, which may or may not be inaccurate for local site conditions. Numerical modelling continues to advance understanding of the behavior of these slope movements; however, building a model is only practical for large or important projects. Empirical relationships between a readily utilized parameter for assessing slope stability, Taylor's stability number, and the observed retrogression distance of past failures have been met with considerable scatter. Additional parameters, which are not easily measured during a forensic study, are affecting retrogression distance. Isolating individual parameters for consideration through repeatable physical models allows for examination of their relative importance and motivation for inclusion in future studies. The objective of this research was to model a retrogressive landslide in a geotechnical centrifuge, perform stability analyses on failure episodes, and to subsequently investigate the relative effect of slope angle and shear strength on retrogression distance.

In this research, novel physical model experiments for sequential retrogression failures in sensitive clay material were performed. A sensitive cement-soil mixture was utilized with the combination of Portland type 3 cement and kaolin, giving a consistent material for testing. Intentionally varying the curing time of the mixture resulted in undrained peak shear strengths varying from 21 to $31 \mathrm{kPa}$ and sensitivities greater than 10 . New physical model experiments incorporated a rectangular block of the soil in the centrifuge box, with a release door acting as an undrained failure vacating the region downslope from the soil block. Five centrifuge model tests were conducted while varying undrained shear strength and slope angle. The physical model experiments produced multiepisodic, sequential retrogressive landslides recorded with high-speed photography. Post-test strength tests showed a maximum strength degradation of approximately half of the peak strength, which was significantly greater than laboratory-measured remolded strength (sensitivity 10). Although not generally applicable, the unique opportunity to perform stability analysis for each failure episode showed agreement between failure modes and occurrences. Physical model results agreed with existing relationships for retrogression distance correlated with stability number and large deformation shear strength.

\section{Data availability}

Data from the physical modelling experiments are available upon request.

\section{Acknowledgements}

This research was supported by the Natural Sciences and Engineering Research Council (NSERC) of Canada, including the Discovery Grants of the second and third authors. The assistance provided by Gerry Piercey, John Barrett, Ryan Phillips, Karl K., and Madison Bailey at C-CORE in St. John's, Newfoundland during the planning, construction, and testing phases of this project is greatly appreciated.

\section{References}

ASTM. 2016. ASTM D4648 / D4648M-16. Standard test methods for laboratory miniature vane shear test for saturated fine-grained clayey soil. ASTM International, West Conshohocken, Pa. Available from www.astm.org. doi:10.1520/ D4648_D4648M-16.

Bernander, S. 2000. Progressive landslides in long natural slopes. Doctoral thesis, Department of Civil, Environmental, and Natural Resources Engineering, Lulea University of Technology, Lulea, Sweden. 204 pp.

Bjerrum, L. 1967. Engineering geology of Norwegian normally-consolidated marine clays as related to settlements of buildings. Géotechnique, 17(2): 83-118. doi:10.1680/geot.1967.17.2.83.

Canadian Geotechnical Society. 2013. Canadian foundation engineering manual 2006 - errata 2013. Canadian Geotechnical Society.

Chaney, R., and Richardson, G. 1988. Measurement of residual/remolded vane shear strength of marine sediments. In Vane shear strength testing in soils: field and laboratory studies. STP10328S. Edited by A. Richards. ASTM International, West Conshohocken, Pa. pp. 166-181. doi:10.1520/ STP10328S.

Demers, D., Robitaille, D., Locat, P., and Potvin, J. 2014. Inventory of large landslides in sensitive clay in the province of Québec, Canada: preliminary analysis. In Landslides in sensitive clays. Advances in Natural and Technological Hazards Research, Vol. 36. Edited by J.-S. L'Heureux, A. Locat, S. Leroueil, D. Demers, and J. Locat. Springer, Dordrecht, the Netherlands. pp. 77-89. doi:10.1007/978-94-007-7079-9_7.

Devenny, D.W. 1975. Strength mechanisms and response of highly sensitive soils to simulated earthquake loading. Thesis, Purdue University.

Dey, R., Hawlader, B., Phillips, R., and Soga, K. 2015. Large deformation finiteelement modelling of progressive failure leading to spread in sensitive clay slopes. Géotechnique, 65(8): 657-668. doi:10.1680/geot.14.P.193.

Garnier, J., Gaudin, C., Springman, S.M., Culligan, P.J., Goodings, D., Konig, D., et al. 2007. Catalogue of scaling laws and similitude questions in geotechnical centrifuge modelling. International Journal of Physical Modelling in Geotechnics, 7(3): 01-23. doi:10.1680/ijpmg.2007.070301. 
Geertsema, M., and L'Heureux, J.S. 2014. Controls on the dimensions of landslides in sensitive clays. In Landslides in sensitive clays: from geosciences to risk management. Edited by J.-S. L'Heureux, A. Locat, S. Leroueil, D. Demers, and J. Locat. Springer, Dordrecht, the Netherlands. pp. 105-117. doi:10.1007| 978-94-007-7079-9_9.

GeoStudio. 2018. GeoStudio version 9.0.4.15639. Geo-Slope International Ltd., Calgary, Alta.

Hungr, O., Leroueil, S., and Picarelli, L. 2014. The Varnes classification of landslide types, an update. Landslides, 11(2): 167-194. doi:10.1007/s10346-013-0436-y.

ISO. 2004. ISO/TS 17892-6: Geotechnical investigation and testing - Laboratory testing of soil - Part 6: Fall cone test. Available from http://www.iso.org/iso/ iso_catalogue/catalogue_tc/catalogue_detail.htm?csnumber=38519.

Kennedy, R.L., Siemens, G.A., and Take, W.A. 2020. On casting clay specimens of bespoke shear strength and sensitivity for landslide modeling. International Journal of Physical Modeling and Geotechnics, 20: 198-211. doi:10.1680/jphmg.18.00082.

Kutter, B.L., and James, R.G. 1989. Dynamic centrifuge model tests on clay embankments. Géotechnique, 39(1): 91-106. doi:10.1680/geot.1989.39.1.91.

L'Heureux, J.-S. 2012. A study of the retrogressive behavior and mobility of Norwegian quick clay landslides. Vol. 1. In Proceedings of the 11th International Symposium on Landslides, Banff, Alta.

Lebuis, J., Robert, J.-M., and Rissmann, P. 1983. Regional mapping of landslide hazard in Québec. SGI Report No. 17. Swedish Geotechnical Institute, Linkoping, Sweden. pp. 205-262.

Locat, A., Leroueil, S., Bernander, S., Demers, D., Jostad, H.P., and Ouehb, L. 2011. Progressive failures in eastern Canadian and Scandinavian sensitive clays. Canadian Geotechnical Journal, 48(11): 1696-1712. doi:10.1139/t11-059.

Locat, A., Leroueil, S., Fortin, A., Demers, D., and Jostad, H.P. 2015. The 1994 landslide at Sainte-Monique, Quebec: geotechnical investigation and application of progressive failure analysis. Canadian Geotechnical Journal, 52(4): 490-504. doi:10.1139/cgj-2013-0344.

Locat, A., Demers, D., Locat, P., and Geertsema, M. 2017. Sensitive clay landslides in Canada. In Proceedings of the 70th Canadian Geotechnical Conference, Ottawa, Ont.

Madabhushi, G. 2015. Centrifuge modelling for civil engineers. CRC Press, London.

Mayne, P. 2014. Interpretation of geotechnical parameters from seismic piezocone tests. In Proceedings of the 3rd International Symposium on Cone Penetration Testing (CPT'14), Las Vegas. Edited by P.K. Robertson and K.I. Cabal. ISSMGE Technical Committee TC 102. pp. 47-73.

Mitchell, R.J., and Markell, A.R. 1974. Flowsliding in sensitive soils. Canadian Geotechnical Journal, 11(1): 11-31. doi:10.1139/t74-002.

Park, D.S., and Kutter, B.L. 2015. Static and seismic stability of sensitive clay slopes. Soil Dynamics and Earthquake Engineering, 79: 118-129. doi:10.1016/j. soildyn.2015.09.006.

Potvin, J., Thibault, C., Demers, D., and Bilodeau, C. 2014. An overview of the mapping of landslide-prone areas and risk management strategies in the province of Québec, Canada. In Landslides in sensitive clays: from geosciences to risk management. Edited by J.-S. L'Heureux, A. Locat, S. Leroueil, D. Demers, and J. Locat. Springer, Dordrecht, the Netherlands. pp. 331-342. doi:10.1007/978-94-007-7079-9_26.

Quinn, P.E., Hutchinson, D.J., Diederichs, M.S., and Rowe, R.K. 2011a. Characteristics of large landslides in sensitive clay in relation to susceptibility, hazard and risk. Canadian Geotechnical Journal, 48(8): 1212-1232. doi:10.1139/t11-039.

Quinn, P.E., Diederichs, M.S., Rowe, R.K., and Hutchinson, D.J. 2011b. A new model for large landslides in sensitive clay using a fracture mechanics approach. Canadian Geotechnical Journal, 48(8): 1151-1162. doi:10.1139/t11-025.
Sasanian, S., and Newson, T.A. 2014. Basic parameters governing the behaviour of cement-treated clays. Soils and Foundations, 54(2): 209-224. doi:10.1016/j. sandf.2014.02.011.

Schofield, A.N. 1980. Cambridge geotechnical centrifuge operations. Géotechnique, 30(3): 227-268. doi:10.1680/geot.1980.30.3.227.

Steward, T., Sivakugan, N., Shukla, S.K., and Das, B.M. 2011. Taylor's slope stability charts revisited. International Journal of Geomechanics, ASCE, 11(4): 348-352. doi:10.1061/(ASCE)GM.1943-5622.0000093.

Tavenas, F., Flon, P., Leroueil, S., and Lebuis, J. 1983. Remoulding energy and risk of slide retrogression in sensitive clays. SGI Report No. 17. Swedish Geotechnical Institute, Linkoping, Sweden. pp. 423-454.

Taylor, D.W. 1937. Stability of earth slopes. Journal of Boston Society of Civil Engineers, 24: 197-246.

Tremblay-Auger, F., Locat, A., Leroueil, S., Locat, P., Demers, D., Therrien, J., and Mompin, R. 2021. The 2016 landslide at Saint-Luc-de-Vincennes, Quebec: geotechnical and morphological analysis of a combined flowslide and spread. Canadian Geotechnical Journal, 58(2): 295-304. doi:10.1139/ cgj-2019-0671.

Varnes, D.J. 1978. Slope movement types and processes. In Landslides: analysis and control. Edited by R.L. Schuster and R.J. Krizek. Transportation Research Board, Special Report 176. National Academy Press, Washington, D.C. pp. 11-33.

Varnes, D.J., and Cruden, D.M. 1996. Chapter 3: Landslide types and processes. In Landslides: investigation and mitigation. Edited by A.K. Turner and R.L. Schuster. National Academy Press, Washington, D.C. pp. 36-75.

White, D.J., Take, W.A., and Bolton, M.D. 2003. Soil deformation measurement using particle image velocimetry (PIV) and photogrammetry. Géotechnique, 53(7): 619-631. doi:10.1680/geot.2003.53.7.619.

Zhang, X., Sheng, D., Sloan, S.W., and Bleyer, J. 2017. Lagrangian modelling of large deformation induced by progressive failure of sensitive clays with elastoviscoplasticity. International Journal for Numerical Methods in Engineering, 112(8): 963-989. doi:10.1002/nme.5539.

Zhang, X., Wang, L., Krabbenhoft, K., and Tinti, S. 2020. A case study and implication: particle finite element modelling of the 2010 Saint-Jude sensitive clay landslide. Landslides, 17: 1117-1127. doi:10.1007/s10346-019-01330-4.

\section{List of symbols}

FS factor of safety

$g$ acceleration due to gravity

$\mathrm{H}$ height

$N$ centrifuge acceleration factor ( $g$ level)

Ns Taylor's stability number

$R$ retrogression distance

St sensitivity

$X$ horizontal distance from original toe of physical model $(\mathrm{mm})$

$\gamma$ unit weight $\left(\mathrm{kN} / \mathrm{m}^{3}\right)$

$\phi$ friction angle $\left(^{\circ}\right)$ 